\title{
Roles of F-box proteins in human digestive system tumors (Review)
}

\author{
JIAN GONG, LIANG LV and JIRONG HUO
}

Department of Gastroenterology, The Second Xiangya Hospital, Central South University, Changsha, Hunan 410011, P.R. China

Received August 5, 2014; Accepted September 16, 2014

DOI: $10.3892 /$ ijo.2014.2684

\begin{abstract}
F-box proteins (FBPs), the substrate-recognition subunit of E3 ubiquitin (Ub) ligase, are the important components of Ub proteasome system (UPS). FBPs are involved in multiple cellular processes through ubiquitylation and subsequent degradation of their target proteins. Many studies have described the roles of FBPs in human cancers. Digestive system tumors account for a large proportion of all the tumors, and their mortality is very high. This review summarizes for the first time the roles of FBPs in digestive system tumorigenesis and tumor progression, aiming at finding new routes for the rational design of targeted anticancer therapies in digestive system tumors.
\end{abstract}

\section{Contents}

1. Introduction

2. The main FBPs Skp2, FBXW7 and $\beta$ TrCP in digestive system tumors

3. Roles of FBPs in esophageal cancer

4. Roles of FBPs in gastric cancer

5. Roles of FBPs in hepatobiliary tumors

6. Roles of FBPs in pancreatic cancer

7. Roles of FBPs in colorectal cancer

8. Conclusions and perspectives

\section{Introduction}

Protein ubiquitylation by the ubiquitin (Ub) proteasome system (UPS) is a post-translational modification that governs a broad array of basic cellular processes, and its defective

Correspondence to: Dr Jirong Huo, Department of Gastroenterology, The Second Xiangya Hospital, Central South University, 139 Middle Renmin Road, Changsha, Hunan 410011, P.R. China

E-mail: huojir008@126.com

Key words: F-box proteins, digestive system neoplasms, ubiquitin Skp Cullin, F-box protein ligases regulation is manifested in various human diseases (1-3). UPS has a crucial role in maintaining and regulating cellular homeostasis (4). The change of ubiquitination is closely related to the occurrence of a wide variety of tumors. The UPS exerts its functions mainly through the concerted efforts of a group of enzymes (5-7) (Fig. 1): the E1 Ub-activating enzyme, E2 Ub-conjugating enzyme, and E3 Ub ligase and $26 \mathrm{~S}$ proteasome. $\mathrm{Ub}$ is activated in an ATP-dependent manner by an Ub-activating enzyme (E1), and then transferred to the active site cysteine of a conjugating enzyme (E2) through a thioester bond. The E3 ligase facilitates the attachment of Ub onto the substrate protein from the E2 enzyme. Next, the Ub proteins are recognized and then degraded by $26 \mathrm{~S}$ proteasome to several small peptides. There are $>1,000$ putative E3 Ub ligases belonging to two major families, the homologous to E6-APC terminus (HECT) type and Ring/Cullin Ligase (RCL) type $(8,9)$. Among the E3 Ub ligase enzymes, the RCL type of E3 ligases contain the largest number of family members, among them, the Skp1-Cullin1-F-box (SCF) E3 ligase complex has recently come to prominence (10-12). The SCF-type E3 ligase complex consists of four units: Skp1, Rbx1 and Cullin1, and F-box protein (FBP), the latter of which being responsible for the substrate targeting specificity of the complex $(13,14)$. FBPs are characterized by $\sim 40$ amino acids. Because this kind of structure domain was originally found in the cycle of F protein (FBXO1), it is named ' $\mathrm{F}$-box structure domain'. Without taking into account the various isoforms that may be produced, 69 human FBPs have been identified so far (10), but only few of them have been well characterized. FBPs have been classified into three categories according to their specific substrate recognition domains (Fig. 2) (15-17). The FBXW subclass containing WD40 repeat domains is composed of 10 proteins. The FBXL family comprises of 22 proteins which are leucine-rich repeat proteins. Other 37 F-box members containing other domains such as zinc finger or ring finger constitute FBXO family. FBPs are attractive candidates for drug discovery because they play pivotal roles in various cancers.

The common digestive system tumors are colorectal cancer, gastric cancer, liver cancer, esophagus cancer and pancreatic cancer (PC). According to the latest global cancer statistics (Table I), colorectal cancer is the third most common malignancy, while gastric cancer, liver cancer and esophagus cancer are ranked the fourth, the fifth, and the 
Table I. Percentage of the five digestive system cancers in all cancers.

\begin{tabular}{lccrr}
\hline Cancer site & The rank in cancers & New cases & The rank in cancers & Cancer deaths \\
\hline Colon/rectum & 3 & $1,233,700$ & 4 & 608,700 \\
Stomach & 4 & 989,600 & 2 & 738,000 \\
Esophageal & 7 & 464,500 & 6 & 406,800 \\
Liver & 5 & 748,300 & 3 & 695,900 \\
Pancreas & 13 & 277,000 & 266,000 \\
All site but skin & & $12,668,500$ & $7,571,500$ \\
Percentage & & $29.30 \%$ & $35.86 \%$ \\
\hline
\end{tabular}

According to the crude global new cancer cases and deaths in cancer registries in 2008 . All global new cases of the five digestive system cancers in 2008 are 3,713 thousand, $29.30 \%$ is estimated to account for all new cancers. All cancer deaths of the five digestive system cancers in 2008 were 271,000 , of these $35.86 \%$ accounts for all the cancer deaths. The percentage given means the estimated percentage of the five digestive system tumors in all global cancers.

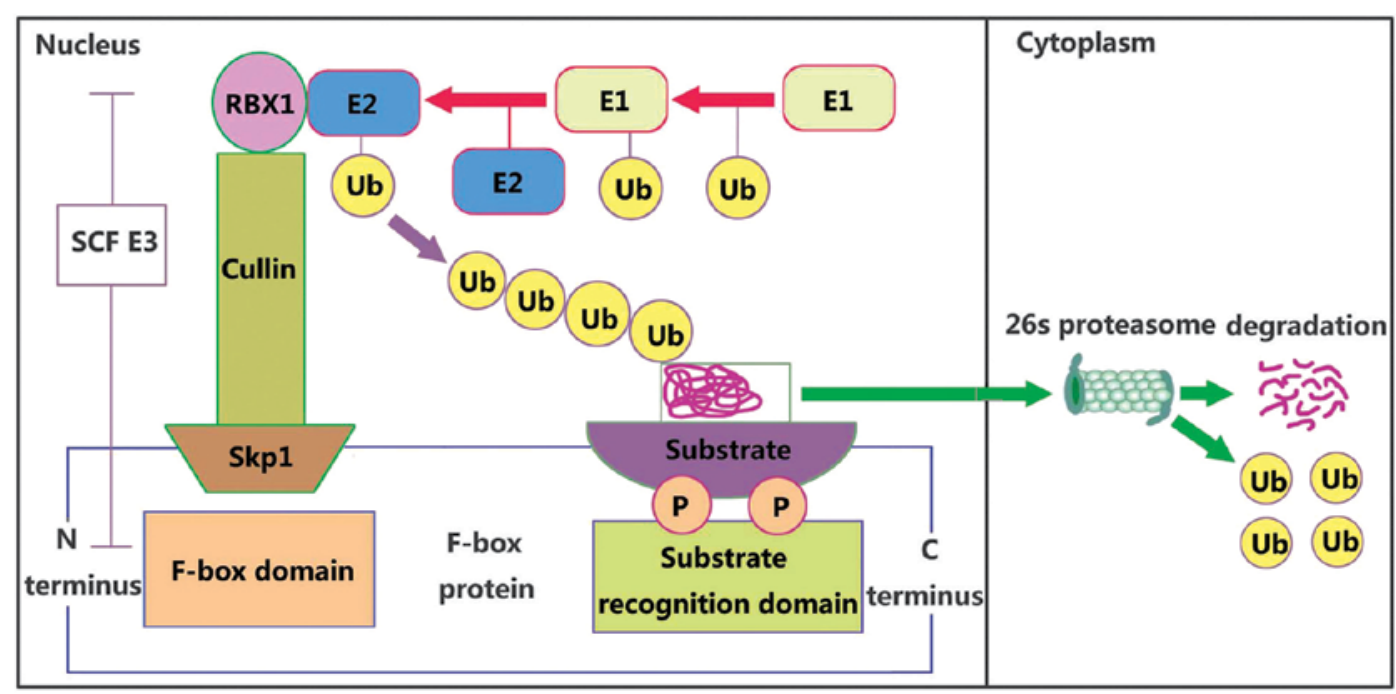

Figure 1. The functions of ubiquitin (Ub) proteasome system (UPS). The E1 enzyme functions as an activator by creating a high-energy thioester bond between a cysteine of the E1 enzyme and the Ub molecule via ATP hydrolysis, which is subsequently transferred to conjugating enzyme (E2). The function of E2 is the transfer of activated $\mathrm{Ub}$ to the site of conjugation in the form of an E2-Ub thiolester intermediate. Ub is then transferred from the E2 to lysine residues in the target through an E3-Ub ligase. Finally the Ub proteins were recognized and then degraded by the 26 s proteasome to several small peptides in the cytoplasm.

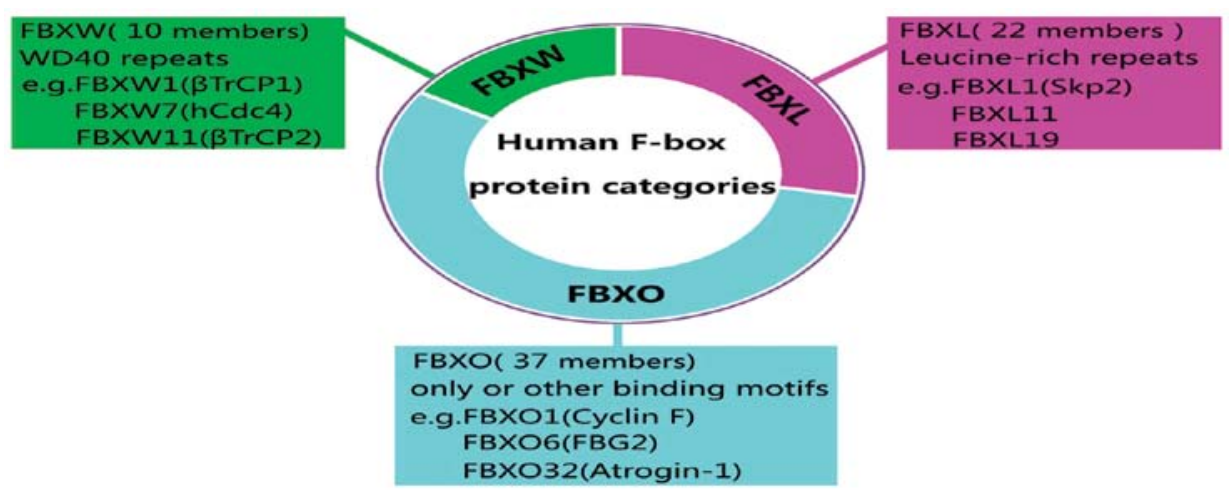

Figure 2. Human F-box protein (FBP) catagories. The large circle stands for the whole FBP family. The three rectangles indicate the three different kinds of FBPs and the typical representatives of each type.

seventh respectively in all cancers. A total of 3,713,100 new cancer cases and 2,715,400 cancer deaths are responsible for $29.30 \%$ of worldwide total new cancer cases and $35.86 \%$ of deaths in 2008. There is a high necessity for accurate 
diagnosis of digestive system tumors because of their poor prognosis due to chemoresistance and a high recurrence rate. The main functions of the digestive tract are the absorption, digestion and excretion. The occurrence and development of digestive system tumors are strongly associated with all sorts of stimulations and the subsequently signal pathway activations caused by stimulations. Studies have shown that FBP, one component of E3 ligase, can be activated by the cell's DNA damage caused by certain stimuli such as heat and chemotherapy drugs $(18,19)$. Therefore, it is necessary and important to summarize the function of FBPs in digestive system cancers.

\section{The main FBPs Skp2, FBXW7 and $\beta$ TrCP in digestive system tumors}

The misregulated degradation of tumor suppressor proteins or oncoproteins can drive tumorigenesis. Accordingly, FBPs can function as oncoproteins when overexpressed (if their substrates are tumor suppressors) or as tumor suppressors (if their substrates are oncoproteins).

$F B X W 7$ is focused on as a tumor suppressor gene in human tumorigenesis in large due to the fact that FBXW7 targets multiple well-known oncoproteins including Cyclin E $(20,21)$, c-Myc $(22,23)$, c-Jun $(24,25)$, Notch $(25,26)$ and tumor suppressor neurofibromatosis type 1 (NF1) (27) for ubiquitination. Gene mutations of FBXW7 are frequently discovered in a variety of human cancers such as cholangiocarcinomas (35\%) (28), digestive system tumors such as colorectal cancer (6-9\%) (29-31), intrahepatic cholangiocarcinoma (ICC) (32) and gastric cancer (3.7\%) (33), esophageal adenocarcinoma (55.6\%) (34), PC (35) and other solid tumors (36-39). Notably, recent studies have also demonstrated that FBXW7 is also involved in the regulation of drug resistance (40-42). Furthermore, FBXW7 is a tumor suppressor and evidence shows that mouse FBXW7 is essential for normal vascular development (43).

S-phase kinase-associated protein 2 (Skp2) is an authenticated oncogenic protein (44). It was first discovered as an element of CDK2/Cyclin A (45). Then it was identified as a Skp1-binding protein to regulate cell cycle progression (46). Skp2 drives cells from $\mathrm{G} 1$ to $\mathrm{S}$ phase through ubiquitylation and degrading the p27 (47). p27, a Cyclin-dependent kinase (CDK) inhibitor, is a negative regulator of the cell cycle which is found decreased in cancers. So far, all studied cases of cancer have indicated that high levels of Skp2 correlate with poor overall survival. The dysregulation of Skp2 and p27 was found to be associated with tumor progression in human oral (48), colon $(49,50)$, esophageal squamous cell carcinoma (ESCC) (51), gastric (52) and prostate cancer (53). Mouse models unequivocally confirmed the role of the Skp2-p27 axis in tumorigenesis (54). Thus, Skp2 may serve as an attractive target for the treatment of cancer.

$\beta$-transducin repeat-containing protein $(\beta \mathrm{TrCP})$ including $\beta \operatorname{TrCP} 1$ and $\beta \operatorname{TrCP} 2$ is overexpressed in multiple cancers, such as colorectal cancer, pancreatic cancer, breast cancer and melanoma, which supports an oncogenic function for these proteins (55). However, in sharp contrast to the tumor-promoting role of $\beta \mathrm{TrCP}$ described above, in gastric cancer tumors, it has been shown to suppress tumor development (56). Thus, $\beta \operatorname{TrCP}$ might have a greater role as an oncogenic protein than as a tumor suppressor in digestive system cancers (55).

\section{Roles of FBPs in esophageal cancer}

Esophageal carcinoma is an age-related neoplasm with a 5-year overall survival rate of $<35 \%(57,58)$. Esophageal cancer is one of the most frequently occurring malignancies and the seventh leading cause of cancer-related deaths in the world. ESCC is the most prevalent type of esophageal cancer in China and the survival rate of ESCC patients is $<10 \%(59,60)$. Due to the changes in lifestyle such as smoking and physical inactivity, the incidence of cancer becomes increasingly high.

Fukuchi et al (51) first analyzed Skp2 and p27 expression in 32 early ESCC surgical specimens. Their findings suggest that the target substrate of Skp2 is mainly p27, and that failure of Skp2-induced degradation of p27 leads to a poor prognosis, especially in the primary stages. Another study (61) reported that Skp2 increases during esophageal squamous cell cancer progression from esophageal intraepithelial dysplasia to ESCC (62). In addition, the elevated expression of Skp2 promoted the radioresistance of ESCC cell line EC9706. Another member of the FBP family, FBXL19, exhibits antitumor property via targeting Rac3 for its degradation, thereby inhibiting TGF $\beta 1$-induced E-cadherin downregulation in esophageal cancer cells OE19 and OE33 (63). Rac3 is a small GTPase multifunctional protein that regulates cell adhesion, migration and differentiation. It has been considered as an oncogene in breast cancer and prostate cancer $(64,65)$. Transforming growth factor- $\beta$ (TGF $\beta$ ), can reduce the tumor suppressor. E-cadherin is a key component in the formation of cell-cell adherens-type junctions in epithelial tissues (66). E-cadherin plays a critical role as a tumor suppressor in cancers (67).

The team of Barbash et al (68) found 14\% (16/116) missense mutations in 116 primary ESCC patients in FBXO4 directly promotes Cyclin D1 accumulation. Taken together, FBXO4 has biological properties consistent with a tumor suppressor in ESCC. As these researchers also found that FBXW8 is not expressed in either normal esophageal epithelium or associated tumor tissues, they speculated that an FBXW8-based E3 ligase is unlikely to contribute to Cyclin D1 proteolysis in ESCC. Cyclin D1 is overexpressed in various types of malignant tumors such as breast cancer (69), and esophageal cancer $(70,71)$. Over the last decade, articles have been published demonstrating that FBPs including FBXO4, FBXW8, Skp2 and FBXO31, independently contribute to Cyclin D1 ubiquitylation $(19,68,72,73)$. However, other researchers found different results (74). Naganawa et al (75) investigated the relationship between the expression of FBXW7 and the tumor progression of 43 primary ESCC patients. The patients with low levels of FBXW7 expression had a significantly shorter postoperative survival time than the patients with high levels of FBXW7 expression.

Kogo et al (76) reported that higher expression of FBXO31 determines poor prognosis in esophageal squamous carcinoma. On the contrary, a substantial body of evidence implicates that FBXO31 functions as a tumor suppressor in cancers such as breast cancer and hepatocellular carcinoma (77-79). So, the molecular mechanism for these discrepancies is so far 
unclear prompting further investigations to identify FBXO31 regulated pathways. A recent study (18) found that FBXO31 downregulates p38 mitogen-activated protein (MAP) kinase via degradation of MAP kinase kinase 6 (MKK6) in ESCC cell lines. p38 MAP plays an important role in a wide range of complex biologic processes, such as cell proliferation, cell differentiation, cell death, cell migration, and invasion, and p38 MAP enhances migration and invasion of many cancers (80). MKK6 is a p38 activator. FBXO32, also known as Atrogin-1, has been reported as an apoptosis regulator and a tumor suppressor (81). FBXO32 has recently been identified as TGF- $\beta$ target gene involved in regulating cell survival and it may be transcriptionally silenced by epigenetic mechanisms in some carcinomas. The mRNA and protein expression of FBXO32 is decreased in esophageal cancer cell lines because of the aberrant methylation and histone deacetylation of FBXO32. The silencing of FBXO32 could be reversed by treatment with 5-aza-2'-deoxycytidine (DNA methylation inhibitor) in the esophageal cancer cell line TE13. This study indicates that FBXO32 may be a functional tumor suppressor in ESCC carcinogenesis and its abnormal methylation leads to the occurrence of ESCC (82).

\section{Roles of FBPs in gastric cancer}

A total of 989,600 new stomach cancer cases and 738,000 deaths are estimated to have occurred in 2008, accounting for $8 \%$ of the total cases and $10 \%$ of total deaths (83). The morbidity of gastric cancer is the second most common, after lung cancer according to global cancer statistics (83).

One study (16) showed that Skp2 is overexpressed in human gastric carcinomas with corresponding reduction of p27 and poor prognosis. Consistently, another study showed that the activation of Skp2 accelerates both p27 and phosphatase and tensin homolog on chromosome 10 (PTEN) degradation in gastric carcinoma $(84,85)$. These studies indicated that p27 and PTEN are the possible substrates of Skp2 in gastric cancers. PTEN is a tumor suppressor. Reduced expression of PTEN protein contributes to carcinogenesis and progression of gastric carcinoma (86). Skp2 expression was gradually increased during the course of intestinal metaplasia, dysplasia and primary gastric carcinoma (84). Knockdown of Skp2 suppressed the ability of gastric cancer MGC803 cells to form tumors and metastasize to the lungs of mice and the growth of established tumors via inhibiting cell proliferation and enhancing cell apoptosis (87). Moreover, another member of the FBXL family, FBXL5, targets cortactin for ubiquitination in gastric cancer cells, thus decreasing cell migration and invasion (88). Cortactin, an actin-interacting protein, is implicated in cytoskeletal architecture and often amplified in advanced, invasive cancers. In other words, FBXL5 may be a tumor suppressor in gastric cancer.

$\beta \operatorname{TrCP} 1$ is not expressed in primary gastric cancer (89). Genetic alterations of $\beta$ TRCP 2 were identified in gastric cancer cell lines and primary gastric cancers (89). Complementing this study, an analysis of somatic mutations in 95 gastric cancer specimens found five missense mutations in $\beta \mathrm{TRCP} 2$, and in these particular tissues, with oncogene $\beta$-catenin level higher than controls (56), which means that $\beta \operatorname{TrCP} 2$ may function as a suppressor in gastric cancer. FBXW7 mutation has been confirmed in gastric cancer (33). The loss of heterozygosity of FBXW7 has reached 32\% in 37 early-onset gastric carcinomas cases (90). Yokobori and colleagues reported the relationship of FBXW7 and p53 in gastric cancer (91). The low expression of FBXW7 mostly results from p53 mutation, which brings about poor prognosis in gastric cancer patients. p53 is well acknowledged as a tumor suppressor gene, and p53 mutation is often found in cancers. Several studies have demonstrated that restoration of wild-type p53 expression can eliminate tumors (92-94).

FBXO6, also named Fbg2, mainly targets checkpoint kinase 1 (Chk1) for ubiquitination and degradation. Low expression of FBXO6 causing Chk1 accumulation might increase tumor cell resistance to chemotherapy drugs $(95,96)$. Chk1 is the main replication checkpoint for cellular sensitivity to replicative stress. It has been proved to be overexpressed in cancers (97). Intriguingly, recent evidence questions the role of FBXO6 in gastric cancer. Zhang et al (98) reported that FBXO6 promotes the growth, proliferation and invasion of gastric cancer cells as well as normal gastric cells. FBXO32 is also involved in promoting tumorigenesis in gastric cancer cells (99).

\section{Roles of FBPs in hepatobiliary tumors}

The mortality rate of liver cancer is second in the ranking in China (100).

There is evidence showing that, troglitazone (101) or LK-A (102) can lower the expression of Skp2 in human hepatoma cells or xenograft models. Troglitazone is a synthetic ligand of peroxisome proliferator-activated receptor- $\gamma$ (PPAR $\gamma)$, and it has an inhibitory effect on cancers (103). LK-A, a natural ent-kaurene diterpenoid isolated from Isodon genus, has an antitumor effect on nasopharyngeal carcinoma (104). Furthermore, Xu et al (105) first reported that knocking down kinesin family member 14 (KIF14) could reduce the expression of Skp2 and elevated p27 in hepatocellular carcinoma cells. KIF14 is a mitotic kinesin and acts as oncogene in cancers (106).

Acetaldehyde contributing to more aggressive phenotypes in hepatocellular carcinoma cell line HEPG2 might result from activating the expression of $\beta \operatorname{TrCP}(107) . F B X W 7$, a universally acknowledged tumor suppressor gene, decreased in hepatocellular carcinoma tissues. FBXW7 was thought to be the strongest independent risk factor for hepatocellular carcinoma recurrence or prognostic marker (108). A recent study shows that Yes-associated protein (YAP) may be a potential target of FBXW7 in hepatocellular carcinoma (109). YAP is often overexpressed in various types of human cancers (110). FBXW7 protein expression was negatively correlated with c-Myc, Cyclin E and p53 in hepatocellular carcinoma tissues (111). Recombinant human adenovirus-p53 can inhibit tumor cell growth with FBXW7 upregulation in murine hepatocellular carcinoma model (112). This provides a new potential therapy for HCC.

Notably, Cyclin F (FBXO1), is downregulated in liver cancer, indicating poor survival and recurrence (113). FBXO5, named early mitotic inhibitor-1 (Emi1), is highly expressed in 114 human hepatocellular carcinoma samples. Emil increases hepatocellular carcinoma cell proliferation 


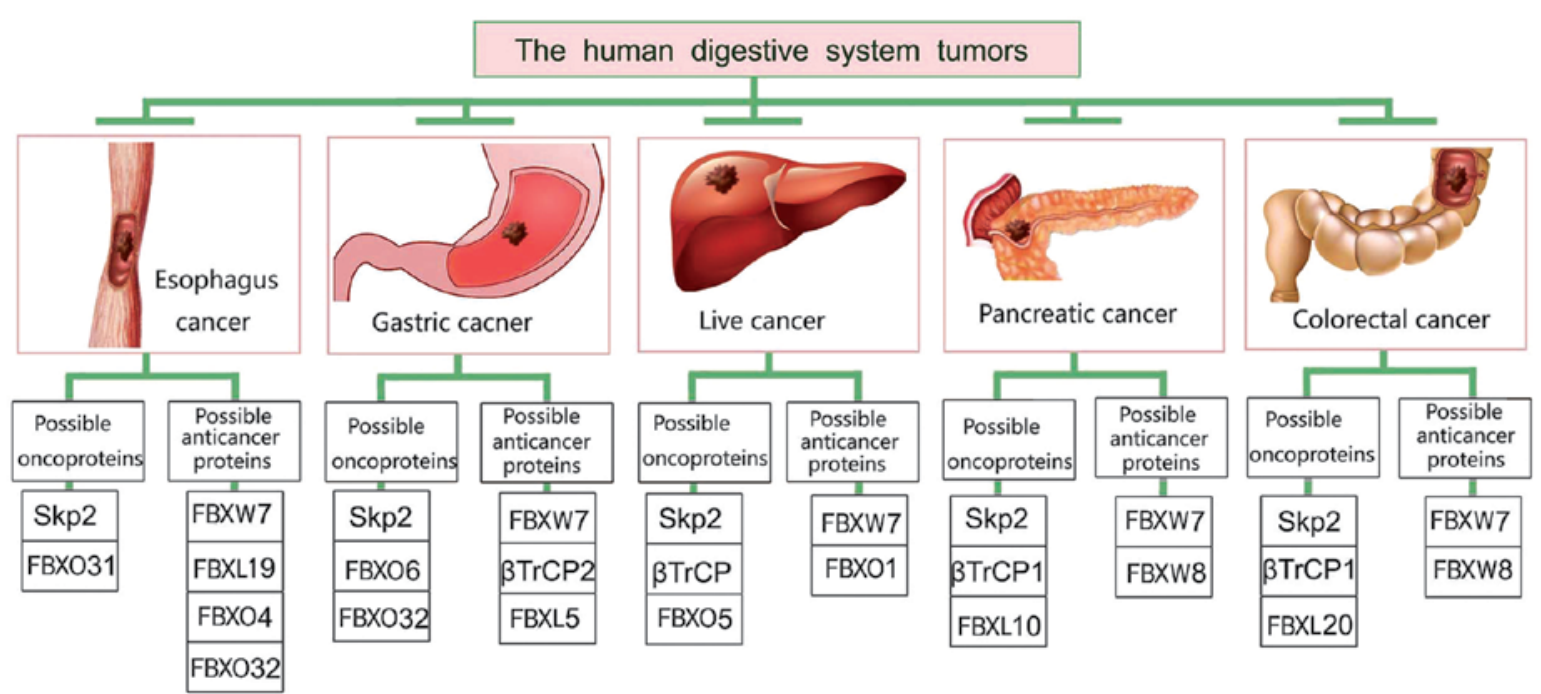

Figure 3. The five common digestive system tumors and the possible oncoproteins or anticancer proteins in the corresponding tumor.

by inhibiting the degradation of Skp2, thus reducing the expression of p27 (114). This result indicates possible crosstalk between individual FBPs. FBXO31 functions as a tumor suppressor mainly through the degradation of Cyclin D1 in liver cancer (77), which is consistent with the results in breast cancer (79).

One study showed that Skp2 is also overexpressed in both biliary tract carcinoma (BTC) cell lines and primary BTC predicting poor prognosis. However, the levels of Skp2 in BTC and p27 proteins were not correlated inversely with other tumors (115). Also p27 can be degraded by other means in BTC. Data from another study reported that the expression of p27 and Skp2 are significantly inversely correlated in 74 patients with ICCs (116). Silencing of the $S k p 2$ gene can on one hand slow down the growth in a nude mouse tumor model, and on the other hand, inhibit the proliferation, migration and invasiveness of gallbladder carcinoma cell line GBC-SD by enhancing the expression of the p27 protein (117). Loss of FBXW7 expression is correlated with lymph node metastasis in ICC, which tends to be an independent prognostic factor for both overall and disease-free survival (32).

\section{Roles of FBPs in pancreatic cancer}

Pancreatic cancer (PC) is rare, with the incidence rate $2.5 \%$ of all forms of cancers, while the mortality rate has reached 96\% (118). Because the conventional treatments of PC have little effect on disease course, the 5-year survival of PC is $<5 \%(119,120)$. Most patients die within the first year of diagnosis (121). Therefore, better in-depth knowledge of the molecular mechanisms might reveal new avenues for early diagnosis, and treatment of patients.

The FBPs have rarely been studied in human PC. It has been accepted by researchers that expression of Skp2 is high in many advanced cancers. Consistent with a putative oncogenic role, high expression level of Skp2 correlating with histological grade, lymph node metastasis, lymphatic permeation and poor outcome has been implicated in human pancreatic ductal carcinoma tissue (122). Schüler et al disclosed for Skp2 a novel function in pancreatic ductal adenocarcinoma (PDAC) cells. Skp2 can resist TNF-related apoptosis-inducing ligand (TRAIL)-induced apoptosis (123). Blocking the expression of $\beta$ TRCP1 in PC cell line PancTu-1 can reduce nuclear factor $-\kappa \mathrm{B}(\mathrm{NF}-\kappa \mathrm{B})$ activation and chemoresistance (124). FBXW7 mutations were found in PC (35). Genistein, a soy derived isoflavone, exerts its antitumor activity partly through the upregulation of FBXW7 and downregulation of miR-223 in PC cells (125). Knockdown of FBXW8 can inhibit cell proliferation of PC cells (126). FBXL10, a nucleolar protein that represses transcription of ribosomal RNA genes (127), can promote leukemia mouse model development (128), but its expression is low in aggressive brain tumors (127). The expression of FBXL10 is high in human PC tissues, and higher expression levels of FBXL10 are correlated with disease grade and stage, as well as metastasis. FBXL10 overexpression co-operated with KrasG12D, which promotes PDAC formation in mouse models (129).

\section{Roles of FBPs in colorectal cancer}

Colorectal cancer is the second most diagnosed cancer in females and the third leading cause of cancer-related death for females with an estimated 1.2 million new cases and 608,700 deaths in 2008 (3). Colorectal cancer incidence rates are rapidly increasing in several areas $(130,131)$.

Li et al (132) reported a progressive increase of Skp2 from normal mucosa through adenoma to primary carcinoma during all stages of colorectal carcinogenesis. In the contrary, expression of Skp2, was decreased during invasion but increased again in colorectal tumor metastases. Similar results were also detected in melanoma (133). Overexpression of Skp2 accompanied with reduced p27 indicates overall survival in colorectal carcinoma patients (134). Xu et al (135) reported the effect of interfering Skp2 expression in colon carcinoma cell line SW480. Their results showed that knockdown of Skp2 expression induced p27 and p16 upregulation. It can also block tumor cell growth and induce cell apoptosis 
in colorectal cancer nude mice. Recently, another study (136) also revealed that siRNA knockdown of Skp2 caused p27 accumulation in colon carcinoma cell line SW620, as well as increased the survival rate of nude mice. Zhu et al (137) reported that FBXL20 promotes carcinogenesis through activating of the Wnt signaling pathway and caspase in human colorectal adenocarcinoma. Later, it was reported that FBXL20 overexpression increases the invasiveness of colorectal cancer cell line Lovo by mediating the ubiquition and degradation of E-cadherin (138). These findings collectively indicate that FBXL20 might also govern tumorigenesis in colorectal adenocarcinoma.

Okabe et al (72) reported that FBXW8 targets Cyclin D1, and FBXW7 targets Cyclin E for degration in colorectal cancer cells HCT116 and SW480. Babaei-Jadidi et al (139) specifically deleted FBXW7 in the murine gut, and their results showed that the loss of FBXW7 accelerated intestinal tumorigenesis, promoting accumulation of $\beta$-catenin in adenomas at late but not early time points. Somatic mutations of FBXW7 in colorectal adenocarcinoma tissues were first detected by Rajagopalan et al (140) and later verified by many studies (29-31). The absence of FBXW7 enhanced expression of c-Myc and Cyclin E proteins and upregulated cell proliferation (30) as well as activated Wnt and Notch signaling pathway in human colorectal carcinoma (141). Jahid et al (142) reported that miR-27a can directly downregulate FBXW7 and promote cell proliferation through activating Notch, Jun and Myc signaling in colorectal cancer cell lines. Wang et al (143) first reported that depletion of FBXW7 induces epithelial-mesenchymal transition (EMT) in human colon cancer cells, which can be suppressed by mTOR inhibitor rapamycin. This result indicates that FBXW7/mTOR axis could be a novel EMT pathway that mediates cancer invasion.

Earlier observation demonstrates that $\mathrm{I} \kappa \mathrm{B}$ and $\beta$-catenin have a similar motif for the degradation via UPS pathway, indicating that the ubiquitination of the two proteins is mediated by the same E3 ligase (144). I $\kappa$ B, inhibitor of $\mathrm{NF}-\kappa \mathrm{B}$, functions as a tumor suppressor. $\beta$-catenin is a downstream molecule of Wnt signaling pathways. $\beta$-catenin is an oncoprotein that was found routinely activated in tumors and has been correlated with poor prognosis and short survival $(145,146)$. $\beta$ TrCP targeting the degradation of both $\beta$-catenin and I $\mathrm{B}$ has been verified $(147,148)$. Ougolkov et al (149) reported that 56\% (25/45) of the tumors had increased $\beta \operatorname{TrCP} 1$ mRNA aånd protein levels in colorectal cancer compared to the normal colorectal tissues. Increased $\beta$ TrCP1 levels were significantly associated with $\beta$-catenin activation. This result indicated that $\beta \mathrm{TrCP} 1$ may act as an oncogene in colorectal cancer.

\section{Conclusions and perspectives}

During the last 10 years since the identification and annotation of the FBP family, the continued identification and characterization of novel substrates has greatly expanded our knowledge. To date, 69 FBPs have been identified in humans. However, only Skp2, FBXW7 and $\beta$ TrCP are well recognized with their matched downstream substrate in different cancers. The identification of substrates for FBPs in different tissues remains a major endeavor for researchers.
Above all, FBPs are important in the occurrence and development of digestive system tumorigenesis, leading the high level research into the pathogenesis of these tumors. We should reveal further mechanism of the FBPs on the cellular and molecular levels. Although a great number of FBPs have been identified in digestive system tumors (Fig. 3), this area of research and our current understanding of the FBP family remains in its infancy. Plenty of questions remain to be answered. Do the FBPs in a cell compete for binding to the Cullin scaffold and consequently are unable to participate in ubiquitination reactions in digestive system tumors? Will a certain FBP function as a tumor suppressor or be oncogenic in different stages of disease or different tissues of the same digestive system tumor? Does intricate crosstalk exist among FBPs in digestive system tumors? How does the FBP's expression vary after primary carcinomas metastasizing to lymph nodes in digestive system tumors? Future study on FBP activity in these digestive system tumors will be of great interest and the different biological characteristics of a given FBP in different tissues will surely bring us new insight. Bortezomib, a reversible inhibitor of the catalytic activity of the $26 \mathrm{~S}$ proteasome, has revealed effectiveness in the treatment of mantle cell lymphoma and multiple myeloma $(150,151)$. In addition, we believe inhibitors targeting the FBPs are promising in the prevention and treatment of digestive system tumors.

\section{Acknowledgements}

We are grateful to Liang Lv for graphic support, and Dr Jirong Huo for English form revision of the review.

\section{References}

1. Genschik P, Sumara I and Lechner E: The emerging family of CULLIN3-RING ubiquitin ligases (CRL3s): cellular functions and disease implications. EMBO J 32: 2307-2320, 2013.

2. Ciechanover A, Orian A and Schwartz AL: Ubiquitin-mediated proteolysis: biological regulation via destruction. Bioessays 22: 442-451, 2000.

3. Smalle J and Vierstra RD: The ubiquitin 26S proteasome proteolytic pathway. Annu Rev Plant Biol 55: 555-590, 2004.

4. Crusio KM, King B, Reavie LB and Aifantis I: The ubiquitous nature of cancer: the role of the $\mathrm{SCF}(\mathrm{Fbw} 7)$ complex in development and transformation. Oncogene 29: 4865-4873, 2010.

5. Hershko A: The ubiquitin system for protein degradation and some of its roles in the control of the cell division cycle. Cell Death Differ 12: 1191-1197, 2005.

6. Pickart CM and Rose IA: Functional heterogeneity of ubiquitin carrier proteins. J Biol Chem 260: 1573-1581, 1985.

7. Jadhav T and Wooten MW: Defining an embedded code for protein ubiquitination. J Proteomics Bioinform 2: 316, 2009.

8. Nakayama KI and Nakayama K: Ubiquitin ligases: cell-cycle control and cancer. Nat Rev Cancer 6: 369-381, 2006.

9. Jackson S and Xiong Y: CRL4s: the CUL4-RING E3 ubiquitin ligases. Trends Biochem Sci 34: 562-570, 2009.

10. Wang Z, Liu P, Inuzuka H and Wei W: Roles of F-box proteins in cancer. Nat Rev Cancer 14: 233-247, 2014.

11. Hicke L, Schubert HL and Hill CP: Ubiquitin-binding domains. Nat Rev Mol Cell Biol 6: 610-621, 2005.

12. Cardozo T and Pagano M: The SCF ubiquitin ligase: insights into a molecular machine. Nat Rev Mol Cell Biol 5: 739-751, 2004.

13. Nandi D, Tahiliani P, Kumar A and Chandu D: The ubiquitin-proteasome system. J Biosci 31: 137-155, 2006.

14. Zheng N, Schulman BA, Song L, et al: Structure of the Cul1-Rbx1-Skp1-F box ${ }^{\text {Skp2 }}$ SCF ubiquitin ligase complex. Nature 416: 703-709, 2002. 
15. Cenciarelli C, Chiaur DS, Guardavaccaro D, et al: Identification of a family of human F-box proteins. Curr Biol 9: 1177-1179, 1999.

16. Winston JT, Koepp DM, Zhu C, et al: A family of mammalian F-box proteins. Curr Biol 9: 1180-1182, 1999

17. Jin J, Cardozo T, Lovering RC, et al: Systematic analysis and nomenclature of mammalian F-box proteins. Genes Dev 18 2573-2580, 2004.

18. Liu J, Han L, Li B, et al: F-box only protein 31 (FBXO31) negatively regulates p38 mitogen-activated protein (MAPK) signaling by mediating lysine 48-linked ubiquitination and degradation of MAP kinase kinase 6 (MKK6). J Biol Chem 289: 21508-21518, 2014.

19. Santra MK, Wajapeyee N and Green MR: F-box protein FBXO31 mediates cyclin D1 degradation to induce G1 arrest after DNA damage. Nature 459: 722-725, 2009.

20. Koepp DM, Schaefer LK, Ye X, et al: Phosphorylation-dependent ubiquitination of cyclin $\mathrm{E}$ by the SCFFbw7 ubiquitin ligase. Science 294: 173-177, 2001

21. Minella AC, Welcker M and Clurman BE: Ras activity regulates cyclin E degradation by the Fbw7 pathway. Proc Natl Acad Sci USA 102: 9649-9654, 2005.

22. Yada M, Hatakeyama S, Kamura T, et al: Phosphorylation-dependent degradation of c-Myc is mediated by the F-box protein Fbw7. EMBO J 23: 2116-2125, 2004

23. Welcker M, Orian A, Jin J, et al: The Fbw7 tumor suppressor regulates glycogen synthase kinase 3 phosphorylation-dependent c-Myc protein degradation. Proc Natl Acad Sci USA 101: 9085-9090, 2004

24. Wei W, Jin J, Schlisio S, et al: The v-Jun point mutation allows c-Jun to escape GSK3-dependent recognition and destruction by the Fbw7 ubiquitin ligase. Cancer Cell 8: 25-33, 2005.

25. Hoeck JD, Jandke A, Blake SM, et al: Fbw7 controls neural stem cell differentiation and progenitor apoptosis via Notch and c-Jun. Nat Neurosci 13: 1365-1372, 2010.

26. Tetzlaff MT, Yu W, Li M, et al: Defective cardiovascular development and elevated cyclin $\mathrm{E}$ and Notch proteins in mice lacking the Fbw7 F-box protein. Proc Natl Acad Sci USA 101: 3338-3345, 2004.

27. Tan M, Zhao Y, Kim SJ, et al: SAG/RBX2/ROC2 E3 ubiquitin ligase is essential for vascular and neural development by targeting NF1 for degradation. Dev Cell 21: 1062-1076, 2011.

28. Akhoondi S, Sun D, von der Lehr N, et al: FBXW7/hCDC4 is a general tumor suppressor in human cancer. Cancer Res 67 9006-9012, 2007.

29. Miyaki M, Yamaguchi T, Iijima T, et al: Somatic mutations of the $C D C 4$ ( $F B X W 7$ ) gene in hereditary colorectal tumors Oncology 76: 430-434, 2009

30. Iwatsuki M, Mimori K, Ishii $\mathrm{H}$, et al: Loss of FBXW7, a cell cycle regulating gene, in colorectal cancer: clinical significance. Int J Cancer 126: 1828-1837, 2010.

31. Kemp Z, Rowan A, Chambers W, et al: CDC4 mutations occur in a subset of colorectal cancers but are not predicted to cause loss of function and are not associated with chromosomal instability. Cancer Res 65: 11361-11366, 2005.

32. Enkhbold C, Utsunomiya T, Morine Y, et al: Loss of FBXW7 expression is associated with poor prognosis in intrahepatic cholangiocarcinoma. Hepatol Res: Feb 19, 2014 (Epub ahead of print).

33. Lee JW, Soung YH, Kim HJ, et al: Mutational analysis of the $h C D C 4$ gene in gastric carcinomas. Eur J Cancer 42: 2369-2373, 2006.

34. Sterian A, Kan T, Berki AT, et al: Mutational and LOH analyses of the chromosome $4 \mathrm{q}$ region in esophageal adenocarcinoma. Oncology 70: 168-172, 2006

35. Calhoun ES, Jones JB, Ashfaq R, et al: BRAF and FBXW7 (CDC4, FBW7, AGO, SEL10) mutations in distinct subsets of pancreatic cancer: potential therapeutic targets. Am J Pathol 163 1255-1260, 2003.

36. Cassia R, Moreno-Bueno G, Rodríguez-Perales $\mathrm{S}$, et al: Cyclin $\mathrm{E}$ gene $(C C N E)$ amplification and $h C D C 4$ mutations in endometrial carcinoma. J Pathol 201: 589-595, 2003.

37. Woo LJ, Hwa SY, Young KS, et al: Somatic mutation of $h C D C 4$ gene is rare in lung adenocarcinomas. Acta Oncol 45: 487-488, 2006.

38. Yan T, Wunder JS, Gokgoz N, et al: hCDC4 variation in osteosarcoma. Cancer Genet Cytogenet 169: 138-142, 2006.

39. Kwak EL, Moberg KH, Wahrer DC, et al: Infrequent mutations of Archipelago ( $h A G O, h C D C 4, F b w 7)$ in primary ovarian cancer. Gynecol Oncol 98: 124-128, 2005.
40. Inuzuka H, Fukushima H, Shaik S, et al: Mcl-1 ubiquitination and destruction. Oncotarget 2: 239-244, 2011.

41. Inuzuka H, Shaik S, Onoyama I, et al: $\mathrm{SCF}(\mathrm{FBW} 7)$ regulates cellular apoptosis by targeting MCL1 for ubiquitylation and destruction. Nature 471: 104-109, 2011.

42. Wertz IE, Kusam S, Lam C, et al: Sensitivity to antitubulin chemotherapeutics is regulated by MCL1 and FBW7. Nature 471: $110-114,2011$.

43. Tsunematsu R, Nakayama K, Oike Y, et al: Mouse Fbw7/Sel-10/Cdc4 is required for notch degradation during vascular development. J Biol Chem 279: 9417-9423, 2004.

44. Gstaiger M, Jordan R, Lim M, et al: Skp2 is oncogenic and overexpressed in human cancers. Proc Natl Acad Sci USA 98: 5043-5048, 2001

45. Zhang H, Kobayashi R, Galaktionov K and Beach D: p19Skp1 and p45Skp2 are essential elements of the cyclin A-CDK2 S phase kinase. Cell 82: 915-925, 1995.

46. Bai C, Sen P, Hofmann K, et al: Skpl connects cell cycle regulators to the ubiquitin proteolysis machinery through a novel motif, the F-box. Cell 86: 263-274, 1996.

47. Carrano AC, Eytan E,Hershko A and Pagano M: Skp2 is required for ubiquitin-mediated degradation of the CDK inhibitor p27. Nat Cell Biol 1: 193-199, 1999.

48. Kudo Y, Kitajima S, Sato S, et al: High expression of S-phase kinase-interacting protein 2 , human F-box protein, correlates with poor prognosis in oral squamous cell carcinomas. Cancer Res 61: 7044-7047, 2001.

49. Hershko D, Bornstein G, Ben-Izhak O, et al: Inverse relation between levels of p27(Kip1) and of its ubiquitin ligase subunit Skp2 in colorectal carcinomas. Cancer 91: 1745-1751, 2001.

50. Mori M, Mimori K, Shiraishi T, et al: p27 expression and gastric carcinoma. Nat Med 3: 593, 1997.

51. Fukuchi M, Masuda N, Nakajima M, et al: Inverse correlation between expression levels of p27 and the ubiquitin ligase subunit Skp2 in early esophageal squamous cell carcinoma. Anticancer Res 24: 777-783, 2004.

52. Masuda TA, Inoue H, Sonoda $\mathrm{H}$, et al: Clinical and biological significance of S-phase kinase-associated protein 2 (Skp2) gene expression in gastric carcinoma: modulation of malignant phenotype by Skp2 overexpression, possibly via p27 proteolysis. Cancer Res 62: 3819-3825, 2002.

53. Yang G, Ayala G, De Marzo A, et al: Elevated Skp2 protein expression in human prostate cancer: association with loss of the cyclin-dependent kinase inhibitor p27 and PTEN and with reduced recurrence-free survival. Clin Cancer Res 8: 3419-3426, 2002.

54. Timmerbeul I, Garrett-Engele CM, Kossatz U, et al: Testing the importance of $\mathrm{p} 27$ degradation by the SCFSkp2 pathway in murine models of lung and colon cancer. Proc Natl Acad Sci USA 103: 14009-14014, 2006.

55. Frescas D and Pagano M: Deregulated proteolysis by the F-box proteins SKP2 and beta-TrCP: tipping the scales of cancer. Nat Rev Cancer 8: 438-449, 2008.

56. Kim CJ, Song JH, Cho YG, et al: Somatic mutations of the beta-TrCP gene in gastric cancer. APMIS 115: 127-133, 2007.

57. Pisani P, Parkin DM and Ferlay J: Estimates of the worldwide mortality from eighteen major cancers in 1985. Implications for prevention and projections of future burden. Int J Cancer 55: 891-903, 1993.

58. Sarbia M, Verreet P, Bittinger F, et al: Basaloid squamous cell carcinoma of the esophagus: diagnosis and prognosis. Cancer 79: 1871-1878, 1997.

59. Berger B and Belka C: Evidence-based radiation oncology: oesophagus. Radiother Oncol 92: 276-290, 2009.

60. Jemal A, Siegel R, Ward E, et al: Cancer statistics, 2008. CA Cancer J Clin 58: 71-96, 2008.

61. Bai P, Xiao X, Zou J, et al: Expression of p14 (ARF), p15 (INK4b), p16 (INK4a) and Skp2 increases during esophageal squamous cell cancer progression. Exp Ther Med 3: 1026-1032, 2012

62. Wang XC, Tian LL, Tian J and Jiang XY: Overexpression of SKP2 promotes the radiation resistance of esophageal squamous cell carcinoma. Radiat Res 177: 52-58, 2012.

63. Dong S, Zhao J, Wei J, et al: F-box protein complex FBXL19 regulates TGF $\beta 1$-induced E-cadherin down-regulation by mediating Rac3 ubiquitination and degradation. Mol Cancer 13: 76, 2014.

64. Engers R, Ziegler S, Mueller M, et al Prognostic relevance of increased Rac GTPase expression in prostate carcinomas. Endocr Relat Cancer 14: 245-256, 2007.

65. Walker MP, Zhang M, Le TP, et al: RAC3 is a pro-migratory co-activator of ER $\alpha$. Oncogene 30: 1984-1994, 2011. 
66. van Roy F and Berx G: The cell-cell adhesion molecule E-cadherin. Cell Mol Life Sci 65: 3756-3788, 2008.

67. Rodriguez FJ, Lewis-Tuffin LJ and Anastasiadis PZ: E-cadherin's dark side: possible role in tumor progression. Biochim Biophys Acta 1826: 23-31, 2012

68. Barbash O, Zamfirova P, Lin DI, et al: Mutations in Fbx4 inhibit dimerization of the SCF(Fbx4) ligase and contribute to cyclin D1 overexpression in human cancer. Cancer Cell 14: 68-78, 2008.

69. Buckley MF, Sweeney KJ, Hamilton JA, et al: Expression and amplification of cyclin genes in human breast cancer. Oncogene 8 2127-2133, 1993

70. Shinozaki H, Ozawa S, Ando N, et al: Cyclin D1 amplification as a new predictive classification for squamous cell carcinoma of the esophagus, adding gene information. Clin Cancer Res 2 $1155-1161,1996$.

71. Ikeguchi M, Sakatani T, Ueta T and Kaibara N: Cyclin D1 expression and retinoblastoma gene protein (pRB) expression in esophageal squamous cell carcinoma. J Cancer Res Clin Oncol 127: 531-536, 2001

72. Okabe H, Lee SH, Phuchareon J, et al: A critical role for FBXW8 and MAPK in cyclin D1 degradation and cancer cell proliferation. PLoS One 1: e128, 2006.

73. Yu ZK, Gervais JL and Zhang H: Human CUL-1 associates with the SKP1/SKP2 complex and regulates p21(CIP1/WAF1) and cyclin D proteins. Proc Natl Acad Sci USA 95: 11324-11329, 1998.

74. Kanie T, Onoyama I, Matsumoto A, et al: Genetic reevaluation of the role of F-box proteins in cyclin D1 degradation. Mol Cell Biol 32: 590-605, 2012

75. Naganawa Y, Ishiguro H, Kuwabara Y, et al: Decreased expression of FBXW7 is correlated with poor prognosis in patients with esophageal squamous cell carcinoma. Exp Ther Med 1: 841-846, 2010.

76. Kogo R, Mimori K, Tanaka F, et al: FBXO31 determines poor prognosis in esophageal squamous cell carcinoma. Int J Oncol 39: 155-159, 2011.

77. Huang HL, Zheng WL, Zhao R, et al: FBXO31 is down-regulated and may function as a tumor suppressor in hepatocellular carcinoma. Oncol Rep 24: 715-720, 2010.

78. Johansson P, Jeffery J, Al-Ejeh F, et al: SCF-FBXO31 E3 ligase targets DNA replication factor Cdt1 for proteolysis in the G2 phase of cell cycle to prevent re-replication. J Biol Chem 289 $18514-18525,2014$.

79. Kumar R, Neilsen PM, Crawford J, et al: FBXO31 is the chromosome 16q24.3 senescence gene, a candidate breast tumor suppressor, and a component of an SCF complex. Cancer Res 65 : 11304-11313, 2005.

80. Dreissigacker U, Mueller MS, Unger M, Siegert P, et al: Oncogenic K-Ras down-regulates Racl and RhoA activity and enhances migration and invasion of pancreatic carcinoma cells through activation of p38. Cell Signal 18: 1156-1168, 2006.

81. Tan J, Yang X, Zhuang L, et al: Pharmacologic disruption of Polycomb-repressive complex 2-mediated gene repression selectively induces apoptosis in cancer cells. Genes Dev 21: 1050-1063, 2007.

82. Guo W, Zhang M, Shen S, et al: Aberrant methylation and decreased expression of the TGF- $\beta /$ Smad target gene FBXO32 in esophageal squamous cell carcinoma. Cancer 120: 2412-2413, 2014.

83. Jemal A, Bray F, Center MM, et al: Global cancer statistics. CA Cancer J Clin 61: 69-90, 2011.

84. Ma XM, Liu Y, Guo JW, Liu JH and Zuo LF: Relation of overexpression of $\mathrm{S}$ phase kinase-associated protein 2 with reduced expression of p27 and PTEN in human gastric carcinoma. World J Gastroenterol 11: 6716-6721, 2005.

85. Ma XM, Liu JH, Guo JW, et al: Correlation of Skp2 expression in gastric carcinoma to expression of P27 and PTEN. Ai Zheng 25: 56-61, 2006 (In Chinese).

86. Yang L, Kuang LG, Zheng HC, et al: PTEN encoding product: a marker for tumorigenesis and progression of gastric carcinoma World J Gastroenterol 9: 35-39, 2003

87. Wei Z, Jiang X, Liu F, et al: Downregulation of Skp2 inhibits the growth and metastasis of gastric cancer cells in vitro and in vivo. Tumour Biol 34: 181-192, 2013

88. Cen G, Ding HH, Liu B and Wu WD: FBXL5 targets cortactin for ubiquitination-mediated destruction to regulate gastric cancer cell migration. Tumour Biol: May 28, 2014 (Epub ahead of print).

89. Saitoh T and Katoh M: Expression profiles of $\beta$ TRCP1 and $\beta T R C P 2$, and mutation analysis of $\beta$ TRCP 2 in gastric cancer. Int J Oncol 18: 959-964, 2001
90. Milne AN, Leguit R, Corver WE, et al: Loss of CDC4/FBXW7 in gastric carcinoma. Cell Oncol 32: 347-359, 2010.

91. Yokobori T, Mimori K, Iwatsuki M, et al: p53-altered FBXW7 expression determines poor prognosis in gastric cancer cases. Cancer Res 69: 3788-3794, 2009.

92. Martins CP, Brown-Swigart L and Evan GI: Modeling the therapeutic efficacy of p53 restoration in tumors. Cell 127: 1323-1334, 2006.

93. Ventura A, Kirsch DG, McLaughlin ME, et al: Restoration of p53 function leads to tumour regression in vivo. Nature 445 : 661-665, 2007.

94. Xue W, Zender L, Miething C, et al: Senescence and tumour clearance is triggered by $\mathrm{p} 53$ restoration in murine liver carcinomas. Nature 445: 656-660, 2007.

95. Zhang YW, Brognard J, Coughlin C, et al: The $\mathrm{F}$ box protein Fbx6 regulates Chk1 stability and cellular sensitivity to replication stress. Mol Cell 35: 442-453, 2009.

96. Merry C, Fu K, Wang J, et al: Targeting the checkpoint kinase Chk1 in cancer therapy. Cell Cycle 9: 279-283, 2010.

97. Verlinden L, Vanden BI, Eelen G, et al: The E2F-regulated gene $C h k l$ is highly expressed in triple-negative estrogen receptor/progesterone receptor/HER-2 breast carcinomas. Cancer Res 67: 6574-6581, 2007.

98.Zhang L, Hou Y, Wang M, et al: A study on the functions of ubiquitin metabolic system related gene $F B G 2$ in gastric cancer cell line. J Exp Clin Cancer Res 28: 78, 2009.

99.Lei KF, Liu BY, Wang YF, et al: SerpinB5 interacts with KHDRBS3 and FBXO32 in gastric cancer cells. Oncol Rep 26 $1115-1120,2011$.

100. Chen WQ, Zeng HM, Zheng RS, et al: Cancer incidence and mortality in china, 2007. Chin J Cancer Res 24: 1-8, 2012.

101. Koga H, Harada M, Ohtsubo M, et al: Troglitazone induces p27Kip1-associated cell-cycle arrest through down-regulating Skp2 in human hepatoma cells. Hepatology 37: 1086-1096, 2003.

102.Liao YJ, Bai HY, Li ZH, et al: Longikaurin A, a natural ent-kaurane, induces $\mathrm{G} 2 / \mathrm{M}$ phase arrest via downregulation of Skp2 and apoptosis induction through ROS/JNK/c-Jun pathway in hepatocellular carcinoma cells. Cell Death Dis 5: e1137, 2014.

103. Yan S, Yang X, Chen T, et al: The PPAR $\gamma$ agonist Troglitazone induces autophagy, apoptosis and necroptosis in bladder cancer cells. Cancer Gene Ther 21: 188-193, 2014.

104.Zou QF, Du JK, Zhang H, et al: Anti-tumour activity of longikaurin A (LK-A), a novel natural diterpenoid, in nasopharyngeal carcinoma. J Transl Med 11: 200, 2013.

105. Xu H, Choe C, Shin SH, et al: Silencing of KIF14 interferes with cell cycle progression and cytokinesis by blocking the p27 (Kip1) ubiquitination pathway in hepatocellular carcinoma. Exp Mol Med 46: e97, 2014

106. Thériault BL, Basavarajappa HD, Lim H, et al: Transcriptional and epigenetic regulation of KIF14 overexpression in ovarian cancer. PLoS One 9: e91540, 2014.

107. Hsiang CY, Wu SL, Chen JC, et al: Acetaldehyde induces matrix metalloproteinase-9 gene expression via nuclear factor-kappaB and activator protein 1 signaling pathways in human hepatocellular carcinoma cells: association with the invasive potential Toxicol Lett 171: 78-86, 2007

108. Imura S, Tovuu LO, Utsunomiya T, et al: The role of Fbxw7 expression in hepatocellular carcinoma and adjacent non-tumor liver tissue. J Gastroenterol Hepatol, Apr 14, 2014 (Epub ahead of print)

109. Tu K, Yang W, Li C, et al: Fbxw7 is an independent prognostic marker and induces apoptosis and growth arrest by regulating YAP abundance in hepatocellular carcinoma. Mol Cancer 13. 110, 2014.

110. Steinhardt AA, Gayyed MF, Klein AP, et al: Expression of Yes-associated protein in common solid tumors. Hum Pathol 39 1582-1589, 2008.

111. Tu K, Zheng X, Zan X, et al: Evaluation of Fbxw7 expression and its correlation with the expression of c-Myc, cyclin $\mathrm{E}$ and p53 in human hepatocellular carcinoma. Hepatol Res 42: 904-910, 2012

112. Tu K, Zheng X, Zhou Z, et al: Recombinant human adenovirus-p53 injection induced apoptosis in hepatocellular carcinoma cell lines mediated by p53-Fbxw7 pathway, which controls c-Myc and Cyclin E. PLoS One 8: e68574, 2013.

113. Fu J, Qiu H, Cai M, et al: Low cyclin F expression in hepatocellular carcinoma associates with poor differentiation and unfavorable prognosis. Cancer Sci 104: 508-515, 2013. 
114.Zhao Y, Tang Q, Ni R, et al: Early mitotic inhibitor-1, an anaphase-promoting complex/cyclosome inhibitor, can control tumor cell proliferation in hepatocellular carcinoma: correlation with Skp2 stability and degradation of p27 (Kip1). Hum Pathol 44: 365-373, 2013.

115. Sanada T, Yokoi S, Arii S, et al: Skp2 overexpression is a p27Kip1-independent predictor of poor prognosis in patients with biliary tract cancers. Cancer Sci 95: 969-976, 2004.

116. Hashimoto N, Yachida S, OkanoK, et al: Immunohistochemically detected expression of $\mathrm{p} 27(\mathrm{Kip} 1)$ and Skp2 predicts survival in patients with intrahepatic cholangiocarcinomas. Ann Surg Oncol 16: 395-403, 2009.

117. Zhang B, Ji LH, Liu W, et al: Skp2-RNAi suppresses proliferation and migration of gallbladder carcinoma cells by enhancing p27 expression. World J Gastroenterol 19: 4917-4924, 2013

118. Ferlay J, Shin HR, Bray F, et al: Estimates of worldwide burden of cancer in 2008: GLOBOCAN 2008. Int J Cancer 127: 2893-2917, 2010.

119. Greenlee RT, Hill-Harmon MB, Murray T and Thun M: Cancer statistics, 2001. CA Cancer J Clin 51: 15-36, 2001.

120.Li D, Xie K, Wolff R and Abbruzzese JL: Pancreatic cancer. Lancet 363: 1049-1057, 2004.

121.Hidalgo M: Pancreatic cancer. N Engl J Med 362: 1605-1617, 2010.

122. Einama T, Kagata Y, Tsuda H, et al: High-level Skp2 expression in pancreatic ductal adenocarcinoma: correlation with the extent of lymph node metastasis, higher histological grade, and poorer patient outcome. Pancreas 32: 376-381, 2006.

123. Schüler S, Diersch S, Hamacher R, et al: Skp2 confers resistance of pancreatic cancer cells towards TRAIL-induced apoptosis. Int J Oncol 38: 219-225, 2011

124. Müerköster S, Arlt A, Sipos B, et al: Increased expression of the E3-ubiquitin ligase receptor subunit betaTRCP1 relates to constitutive nuclear factor-kappaB activation and chemoresistance in pancreatic carcinoma cells. Cancer Res 65: 1316-1324, 2005

125. Ma J, Cheng L, Liu H, et al: Genistein down-regulates miR-223 expression in pancreatic cancer cells. Curr Drug Targets 14 $1150-1156,2013$.

126. Wang H, Chen Y, Lin P, et al: The CUL7/F-box and WD repeat domain containing 8 (CUL7/Fbxw8) ubiquitin ligase promotes degradation of hematopoietic progenitor kinase 1. J Biol Chem 289: 4009-4017, 2014

127. Frescas D, Guardavaccaro D, Bassermann F, et al: JHDM1B/ FBXL10 is a nucleolar protein that represses transcription of ribosomal RNA genes. Nature 450: 309-313, 2007.

128. He J, Nguyen AT and Zhang Y: KDM2b/JHDM1b, an H3K36me2-specific demethylase, is required for initiation and maintenance of acute myeloid leukemia. Blood 117: 3869-3880, 2011

129. Tzatsos A, Paskaleva P, Ferrari F, et al: KDM2B promotes pancreatic cancer via Polycomb-dependent and -independent transcriptional programs. J Clin Invest 123: 727-739, 2013.

130. Center MM, Jemal A and Ward E: International trends in colorectal cancer incidence rates. Cancer Epidemiol Biomarkers Prev 18: 1688-1694, 2009.

131.Center MM, Jemal A, Smith RA and Ward E: Worldwide variations in colorectal cancer. CA Cancer J Clin 59: 366-378, 2009.

132.Li JQ, Wu F, Mai T, et al: Correlation of Skp2 with carcinogenesis, invasion, metastasis, and prognosis in colorectal tumors. Int J Oncol 25: 87-95, 2004.

133. Woenckhaus C, Maile S, Uffmann S, et al: Expression of Skp2 and p27KIP1 in naevi and malignant melanoma of the skin and its relation to clinical outcome. Histol Histopathol 20: 501-508, 2005.
134. Shapira M, Ben-Izhak O, Linn S, et al: The prognostic impact of the ubiquitin ligase subunits Skp2 and Cks1 in colorectal carcinoma. Cancer 103: 1336-1346, 2005.

135. Xu SY, Wang F, Wei G, et al: S-phase kinase-associated protein 2 knockdown blocks colorectal cancer growth via regulation of both p27 and p16 expression. Cancer Gene Ther 20: 690-694, 2013.

136. Chen H, Mo X, Yu J, et al: Interference of Skp2 effectively inhibits the development and metastasis of colon carcinoma. Mol Med Rep 10: 1129-1135, 2014.

137.Zhu J, Li K, Dong L and Chen Y: Role of FBXL20 in human colorectal adenocarcinoma. Oncol Rep 28: 2290-2298, 2012.

138. Zhu J, Deng S, Duan J, et al: FBXL20 acts as an invasion inducer and mediates E-cadherin in colorectal adenocarcinoma. Oncol Lett 7: 2185-2191, 2014

139. Babaei-Jadidi R, Li N, Saadeddin A, et al: FBXW7 influences murine intestinal homeostasis and cancer, targeting Notch, Jun, and DEK for degradation. J Exp Med 208: 295-312, 2011

140.Rajagopalan H, Jallepalli PV, Rago C, et al: Inactivation of hCDC4 can cause chromosomal instability. Nature 428: 77-81, 2004

141. Sancho R, Jandke A, Davis H, et al: F-box and WD repeat domain-containing 7 regulates intestinal cell lineage commitment and is a haploinsufficient tumor suppressor. Gastroenterology 139: 929-941, 2010.

142. Jahid S, Sun J, Edwards RA, et al: miR-23a promotes the transition from indolent to invasive colorectal cancer. Cancer Discov 2: 540-553, 2012

143.Wang Y, Liu Y, Lu J, et al: Rapamycin inhibits FBXW7 loss-induced epithelial-mesenchymal transition and cancer stem cell-like characteristics in colorectal cancer cells. Biochem Biophys Res Commun 434: 352-356, 2013.

144. Aberle H, Bauer A, Stappert J, et al: Beta-catenin is a target for the ubiquitin-proteasome pathway. EMBO J 16: 3797-3804, 1997.

145.Zhang N, Wei P, Gong A, et al: FoxM1 promotes $\beta$-catenin nuclear localization and controls Wnt target-gene expression and glioma tumorigenesis. Cancer Cell 20: 427-442, 2011.

146. Mokkapati S, Niopek K, Huang L, et al: $\beta$-catenin activation in a novel liver progenitor cell type is sufficient to cause hepatocellular carcinoma and hepatoblastoma. Cancer Res 74: 4515-4525, 2014.

147. Shirane M, Hatakeyama S, Hattori K, et al: Common pathway for the ubiquitination of IkappaBalpha, IkappaBbeta, and IkappaBepsilon mediated by the F-box protein FWD1. J Biol Chem 274: 28169-28174, 1999.

148. Spiegelman VS, Slaga TJ, Pagano M, et al: Wnt/beta-catenin signaling induces the expression and activity of betaTrCP ubiquitin ligase receptor. Mol Cell 5: 877-882, 2000.

149. Ougolkov A, Zhang B, Yamashita K, et al: Associations among beta-TrCP, an E3 ubiquitin ligase receptor, beta-catenin, and NF-kappaB in colorectal cancer. J Natl Cancer Inst 96: $1161-1170,2004$

150. Alinari L, White VL, Earl CT, et al: Combination bortezomib and rituximab treatment affects multiple survival and death pathways to promote apoptosis in mantle cell lymphoma. MAbs 1: 31-40, 2009.

151. Kane RC, Bross PF, Farrell AT and Pazdur R: Velcade: U.S. FDA approval for the treatment of multiple myeloma progressing on prior therapy. Oncologist 8: 508-513, 2003. 